\title{
Wilson disease and the differential diagnosis of its hepatic manifestations: a narrative review of clinical, laboratory, and liver histological features
}

\author{
Shannon M. Schroeder ${ }^{1}$, Karen E. Matsukuma ${ }^{2}$, Valentina Medici ${ }^{3} \wedge$ \\ ${ }^{1}$ Department of Internal Medicine, University of California Davis, Sacramento, CA, USA; ${ }^{2}$ Department of Pathology and Laboratory Medicine, \\ University of California Davis, Sacramento, CA, USA; ${ }^{3}$ Department of Internal Medicine, Division of Gastroenterology and Hepatology, University \\ of California Davis, Sacramento, CA, USA \\ Contributions: (I) Conception and design: SM Schroeder, V Medici; (II) Administrative support: None; (III) Provision of study materials or patients: \\ All authors; (IV) Collection and assembly of data: All authors; (V) Data analysis and interpretation: All authors; (VI) Manuscript writing: All authors; \\ (VII) Final approval of manuscript: All authors. \\ Correspondence to: Valentina Medici, MD, FAASLD. Professor, Department of Internal Medicine, Division of Gastroenterology and Hepatology, \\ University of California Davis, 4150 V Street, PSSB Suite 3500, Sacramento, CA 95817, USA. Email: vmedici@ucdavis.edu.
}

Objective: The goal of the present work is to provide an overview of the differential diagnosis of Wilson disease.

Background: Wilson disease is a rare condition due to copper accumulation primarily in the liver and brain. Although there is no definitive cure, current anti-copper treatments are associated with better outcomes if initiated early and if the diagnosis is made promptly. However, diagnostic delays are frequent and often Wilson disease represents a diagnostic challenge. The diagnosis ultimately relies on a combination of clinical, laboratory and genetic findings, and it is crucial that clinicians list Wilson disease in their differential diagnosis, especially in patients presenting with a hepatocellular pattern of liver injury. Some biochemical and liver histological features of Wilson disease overlap with those of more common conditions including nonalcoholic fatty liver disease, alcohol-associated liver disease, and autoimmune hepatitis. In particular, hepatic steatosis, hepatocyte glycogenated nuclei, ballooning degeneration, and Mallory-Denk bodies are often identified in Wilson disease as well as more common liver diseases. In addition, the natural history of liver damage in Wilson disease and the risk of developing liver cancer are largely understudied.

Methods: We conducted an enlarged review of published papers on Wilson disease focusing on its diagnosis and distinctive clinical and liver pathology features in relation to common non-cholestatic liver diseases with the final goal in aiding clinicians in the diagnostic process of this rare but treatable condition.

Conclusions: Aside from markedly altered copper metabolism, Wilson disease has essentially no pathognomonic features that can distinguish it from more common liver diseases. Clinicians should be aware of this challenge and consider Wilson disease in patients presenting with a hepatocellular pattern of liver injury.

Keywords: Wilson disease (WD); copper; diagnosis; histology; fatty liver

Submitted May 04, 2021. Accepted for publication Jul 25, 2021.

doi: $10.21037 / \mathrm{atm}-21-2264$

View this article at: https://dx.doi.org/10.21037/atm-21-2264

^ ORCID: 0000-0001-5438-284X. 


\section{Introduction}

Wilson disease (WD) is an autosomal recessive genetic disease of copper metabolism that results in pathologic deposition of copper in the liver, brain, and other organs and tissues $(1,2)$. The pathogenesis involves diseasecausing variants affecting the $A T P 7 B$ gene localized on the short arm of chromosome $13(3,4)$. Using ATPdependent mechanisms, the ATP7B copper transporter regulates transmembrane copper export and ceruloplasmin maturation through the trans-Golgi network (5). Failure to excrete copper from the hepatocytes results in heterogenous hepatic copper accumulation that evolves as the disease progresses $(6,7)$. In early stages, copper accumulates in hepatic nuclei and triggers the remodeling of liver transcriptome, which involves up-regulation of cell cycle related genes and downregulation of lipid metabolism (8). Cellular copper metabolism and distribution is highly regulated by copper-chaperones and metallothioneins. Copper also accumulates in mitochondria, with consequent effects on energy metabolism (9-11), and in later stages in cytosol lysosomes (12). The initial clinical presentation ranges from mild with asymptomatic transaminitis to severe with decompensated cirrhosis and signs of portal hypertension or acute liver failure (13-16). WD typically presents with hepatocellular rather than cholestatic pattern of liver injury (17). The clinical signs and symptoms as well as the liver pathology are often non-specific and can mimic other common liver diseases including non-alcoholic fatty liver disease (NAFLD), alcoholic hepatitis, and autoimmune hepatitis (AIH) (18-20). The diagnostic process can be arduous as no single laboratory test reliably confirms the diagnosis, which ultimately relies on multiple combined biomarkers and parameters (21-23). This is important because WD is fatal if left untreated, and earlier treatment is linked to better outcomes with reduced morbidity and mortality $(24,25)$. Previous reviews have addressed the differential diagnosis of the neurological manifestations of WD (26) but a similar approach for the hepatic manifestation is lacking. With this work, our goal was to answer the clinician questions on how to differentiate WD from other liver diseases. Therefore, the ultimate objective of this review is to guide practitioners by describing the clinical and laboratory features of WD in relation to common non-cholestatic liver conditions that are included in the differential diagnosis of this rare disease.

We present the following article in accordance with the
Narrative Review reporting checklist (available at https:// dx.doi.org/10.21037/atm-21-2264).

\section{Methods}

We conducted a non-systematic literature search of PubMed articles written in English using the search terms Wilson disease, diagnosis, histology, and Leipzig score. Reviews, original articles, randomized controlled trials, meta-analyses, book chapters, and abstracts presented in conferences up to March 2021 were included. We present a narrative synthesis of extracted data.

\section{Serum ceruloplasmin levels}

Traditionally, total ceruloplasmin levels are considered diagnostic of WD when below $20 \mathrm{mg} / \mathrm{dL}$. Although most clinical laboratories will implement an immunological method to quantify ceruloplasmin protein, the enzymatic assay quantifying its oxidase activity is ideal to determine ceruloplasmin levels, usually lower than $0.1 \mathrm{~g} / \mathrm{L}$ (27) in WD. Ceruloplasmin levels have been found to be reduced in other chronic liver diseases, mostly as a consequence of cirrhosis and impaired liver function (28). Serum ceruloplasmin levels of WD patients are, on average, significantly lower $(<0.1 \mathrm{~g} / \mathrm{L})$ than those of healthy subjects and patients with other liver diseases, although there can be overlap with other acute or chronic liver conditions. In addition, serum ceruloplasmin can be falsely elevated in WD during acute inflammatory response. Low ceruloplasmin activity has been also described in patients with NAFLD (29). Therefore, overall serum ceruloplasmin is characterized by low sensitivity and specificity for the diagnosis of WD and is of limited value in discerning the differential diagnosis.

\section{Urinary copper concentration}

The urinary copper concentration is a relatively simple and sensitive test for the diagnosis of WD. In untreated WD patients, the 24-hour copper urinary excretion reflects the amount of non-ceruloplasmin-bound copper in the circulation (30). Diagnostic cut-offs and ranges depend on the laboratory. The literature favors cut-offs $>1.6 \mu \mathrm{mol} / 24 \mathrm{~h}$ (>100 $\mu \mathrm{g} / 24 \mathrm{~h})(13,14,27,31)$. However, multiple studies have shown this cut-off to be too high in the pediatric setting $(32,33)$. One study showed higher diagnostic accuracy using a $40 \mu \mathrm{g} / 24 \mathrm{hr}$ cut-off versus 
the $100 \mu \mathrm{g} / 24 \mathrm{hr}$ cut-off, and although non-significant in healthy individuals, it was shown to be suggestive of WD in asymptomatic children (21). Other liver diseases can cause false positive 24-hour urine copper levels. In AIH, cholestasis, as well as chronic or acute liver failure, urinary copper excretion can be increased, although levels tend to be overall lower than those found in WD $(31,34,35)$.

\section{Hepatic copper concentration}

The cut-off for hepatic copper concentration for the diagnosis of WD is $250 \mu \mathrm{g} / \mathrm{g}$ dry liver tissue $(>4 \mu \mathrm{mol} / \mathrm{g}$ per 2012 European Association for the Study of the Liver guidelines) (27). Although there are increasing data supporting the validity of non-invasive assessment of liver fibrosis in WD (36,37), quantification of hepatic copper is still a major component of the diagnosis of WD. A study from China (38) prospectively evaluated hepatic copper content quantified in the entire liver biopsy specimen obtained from patients with suspected WD compared to multiple other liver conditions for which the liver biopsy was clinically indicated. Liver samples were based on two percutaneous core biopsies to allow for hepatic copper quantification in the entire liver sample which was at least $1 \mathrm{mg}$ of dry weight. The diagnosis of WD was established in 178 patients and the cut-off value of $209 \mu \mathrm{g} / \mathrm{g}$ dry weight was characterized by a sensitivity of $99.4 \%$, specificity of $96.1 \%$, and the best diagnostic accuracy for WD. Whereas nonalcoholic steatohepatitis (NASH) patients presented hepatic copper levels lower than normal range, 19 patients out of 50 with AIH had hepatic copper $>75 \mu \mathrm{g} / \mathrm{g}$ and $2 \mathrm{had}>250 \mu \mathrm{g} / \mathrm{g}$ dry weight. As expected, almost $50 \%$ of patients with cholestatic autoimmune conditions, primary biliary cholangitis and primary sclerosing cholangitis, presented high hepatic copper concentrations $>250 \mu \mathrm{g} / \mathrm{g}$, with an average of $318 \pm 299 \mu \mathrm{g} / \mathrm{g}$ dry weight. A previous study from Ferenci et al. (39) assessed hepatic copper concentration in $3-5 \mathrm{~mm}$ sections of core fresh liver biopsies from patients with WD and patients with other conditions including NASH, alcohol-related hepatitis, and AIH. The sensitivity and specificity of the traditional cut-off of $250 \mu \mathrm{g} / \mathrm{g}$ was $83.3 \%$ and $98.6 \%$, respectively. One patient with alcoholic steatohepatitis and one patient with chronic hepatitis C were also found with elevated hepatic copper $>250 \mu \mathrm{g} / \mathrm{g}$. Therefore, it is likely that the size of the liver biopsy and the ability to measure copper in the whole sample affect the accuracy of the analysis.

\section{${ }^{64} \mathrm{Cu}$ radioactive copper}

Dynamic assessment of copper metabolism and fluxes in the body can be evaluated with radioactive copper tracer ${ }^{64} \mathrm{Cu}$. Interestingly, ${ }^{64} \mathrm{Cu}$ incorporation into ceruloplasmin has demonstrated excellent diagnostic accuracy in patients with WD compared to heterozygous control subjects. In particular this non-invasive test showed higher diagnostic accuracy, sensitivity, and specificity when compared to other parameters of copper metabolism, including ceruloplasmin, total serum copper, non-ceruloplasmin-bound copper, and 24-hour urinary copper excretion $(40) .{ }^{64} \mathrm{Cu}$ tracer in association with positron emission tomography can also be used to dynamically study copper fluxes in the body and holds great promise for diagnostic assessment and research in the field of human conditions associated with altered copper metabolism (41).

\section{ATP7B variants and genetic analysis}

Genetic analysis for $A T P 7 B$ variants is an important tool in the differential diagnosis but, with current knowledge, cannot be considered a gold standard. The $A T P 7 B$ gene analysis can be performed through polymerase chain reaction for detection of known point mutations, whole genome sequencing or whole-exome sequencing. The main challenges of this approach are that the presence of $A T P 7 B$ variants does not predict clinical manifestations of WD or, vice-versa, the lack of variant detection cannot completely exclude the diagnosis. However, it is important to point out that the knowledge about disease-causing $A T P 7 B$ variants is growing together with our capacity to interpret their significance and clinical implications. Therefore, it is possible that genetic studies will soon have a major role in the differential diagnosis.

\section{ATP7B peptides}

Antibodies against selected ATP7B peptides, ATP7B 887 and ATP7B 1056, have shown high sensitivity and specificity for the diagnosis of WD $(42,43)$. The peptides can be measured in small amounts of dried blood spots potentially offering a new accessible tool for the early diagnosis of WD. It is unknown if these peptides will differentiate patients with WD from other chronic liver diseases or if their levels will show differences according to WD phenotype, but they have the potential to expand the current diagnostic options for WD. 


\section{Kayser-Fleischer rings}

The characteristic copper deposits in the cornea at the level of the Descemet's membrane are a frequent manifestation of WD and present in virtually all patients with neurological symptoms. These rings are not pathognomonic as cholestatic liver diseases and chronic hepatitis can also present similar copper deposition in the cornea. However, determining the presence of the Kayser-Fleischer rings when eventually associated with any severity of liver or brain involvement, is a useful part of the diagnostic process. The rings can be identified with slit-lamp examination and with anterior segment optical coherence tomography (ASOCT) evaluation, which can provide objective and accurate quantitative measurement, of the rings, also helpful to assess response to treatment over time $(44,45)$.

\section{Clinical presentation and diagnostic criteria}

The age at presentation of clinically symptomatic WD is usually between the second and fourth decade of life. However, younger and older ages have been extensively reported at WD onset. Patients with WD can present with a wide range of hepatic, neurological, and psychiatric manifestations, combined in various and unpredictable ways. Neurological symptoms include dystonia, tremors and Parkisonism with rigidity and gait disturbances, as well as dysarthria, salivation, and dysphagia. Psychiatric manifestations vary from mood disorders, including depression and bipolar disorders, to personality disorders, including antisocial behavior and sexual disinhibition, and cognitive impairment. Although neuro-psychiatric symptoms are often associated with liver disease, there is no correlation between the severity of the two. Given that WD is an autosomal recessive disorder, it should be considered for all cases of hepatic or neurological symptoms and known family history of WD.

In 2001 at the 8th International Meeting on WD in Leipzig, Germany, a composite scoring system now referred to as the Leipzig score was developed (46). It combines the assessment of clinical and laboratory findings (Kayser-Fleischer rings, neurological symptoms, serum ceruloplasmin, Coombs-negative hemolytic anemia, hepatic and urinary copper levels) with genetic data to aid in the diagnosis of WD.

The authors recommended that prospective studies should be performed to validate this scoring system. However only a handful of small scale prospective and larger retrospective studies have been performed with the aim of validating this score. The results of these studies are summarized in Table 1. The Leipzig score remains a useful tool in the diagnostic process of WD but further studies are needed to validate its significance.

\section{Laboratory and liver histopathological features of common liver diseases in the differential diagnosis of WD}

Clinical laboratory and histological features of WD and liver conditions included in its differential diagnosis are summarized in Tables 2,3. In WD, AST and ALT elevations are typically $2-5$ times the upper limit of normal $(17,52)$ with AST levels usually higher than ALT, likely due to mitochondria function impairment. In cases of advanced disease, the AST/ALT ratio is often $>1$, although this is seen in patient with severe fibrosis/cirrhosis regardless of the underlying etiology.

Copper accumulation in WD is often associated with steatosis and glycogenated hepatocyte nuclei (GN) (Figure 1A) $(53,54)$. Other features described in WD include hepatocyte ballooning degeneration (Figure 1B) and anisonucleosis (Figure 1C), which could both support the diagnosis of WD.

The histologic features of WD differ based on stage of disease. In the early stages, relatively mild, non-specific lobular changes are noted. Scattered apoptotic hepatocytes and spotty necrosis (i.e., focus of lymphocytes surrounding an injured hepatocyte) throughout the lobule are also observed. Mild macrovesicular steatosis may be present. Occasional ballooned hepatocytes (enlarged hepatocytes with cleared out cytoplasm) may be seen. Glycogenated hepatocyte nuclei may be identified in peri-portal hepatocytes. As the disease progresses, inflammation within the portal tracts increases, interface activity (hepatocyte necrosis at the portal tract-lobule interface) develops and hepatocyte ballooning increases. Bridging fibrosis and ultimately cirrhosis develop. In the later stages, hepatocyte anisonucleosis may also be a prominent feature. In acute liver failure, marked hepatocellular degeneration and parenchymal collapse, typically on the background of cirrhosis, is often present. Parenchymal apoptosis of hepatocytes is also a prominent feature. Histochemical stains such as rhodanine or rubeanic acid, by binding directly to copper $(55,56)$, may show increased copper accumulation in hepatocytes. However, the absence of copper deposition does not exclude $\mathrm{WD}$, as hepatic copper 
Table 1 Summary of studies applying the Leipzig score criteria

\begin{tabular}{|c|c|c|c|}
\hline Ref. No. & $\begin{array}{l}\text { Population and study } \\
\text { design }\end{array}$ & Main findings & Laboratory cutoffs \\
\hline $\begin{array}{l}\text { Koppikar, } \\
2005, \\
\text { United } \\
\text { Kingdom } \\
(47)\end{array}$ & $\begin{array}{l}\text { Retrospective cohort } \\
\text { study of } 142 \text { children with } \\
\text { liver disease investigated } \\
\text { for WD in the differential } \\
\text { diagnosis, or screened } \\
\text { after an index case of WD } \\
\text { in the family }\end{array}$ & $\begin{array}{l}\text { - } 53 \text { of } 54 \text { WD had a score } \geq 4 \\
\text { - } 3 \text { patients in the non-WD group had a score } \geq 4 \\
\text { - Sensitivity } 98.14 \% \\
\text { - Specificity } 96.59 \% \\
\text { - PPV } 94.64 \% \\
\text { - NPV } 98.83 \%\end{array}$ & $\begin{array}{l}\text { - Liver copper }>250 \mathrm{mg} \% \text { dry weight } \\
\text { - Serum ceruloplasmin }<20 \mathrm{~g} / \mathrm{L} \\
\text { - Urine copper (pre-penicillamine) } \\
>1 \mathrm{mmol} / 24 \mathrm{~h} \text {, post-penicillamine } \\
425 \mathrm{mmol} / 24 \mathrm{~h}\end{array}$ \\
\hline $\begin{array}{l}\text { Moores, } \\
2012, \\
\text { Canada } \\
(48)\end{array}$ & $\begin{array}{l}\text { Retrospective cohort study } \\
\text { of } 48 \text { adult WD patients in } \\
\text { the ambulatory setting }\end{array}$ & $\begin{array}{l}\text { - } 44 \text { of } 59 \text { patients had a LS } \geq 4 \\
\text { - Median LS in neurological presenting patients was } \\
\text { 8, which was significantly higher }(P=0.002) \text { compared } \\
\text { with those with hepatic presentation (median } 5 \text { ) and } \\
\text { asymptomatic presentation (median } 6 \text { ) }\end{array}$ & $\begin{array}{l}\text { - Ceruloplasmin }<0.20 \mathrm{~g} / \mathrm{L} \\
\text { - Urinary copper }>0.60 \mu \mathrm{mol} / \mathrm{L} \\
\text { - Serum copper }<11.3 \mu \mathrm{mol} / \mathrm{L}\end{array}$ \\
\hline $\begin{array}{l}\text { Penon- } \\
\text { Portmann, } \\
2019 \\
\text { Costa Rica } \\
(49)\end{array}$ & $\begin{array}{l}\text { Retrospective cohort } \\
\text { study of } 140 \text { pediatric WD } \\
\text { patients with molecular } \\
\text { ATP7B testing between } \\
2010 \text { and } 2015\end{array}$ & $\begin{array}{l}\text { - } 100 \% \text { sensitivity: } \text { A total of } 34 \text { pediatric patients, } \\
\text { from } 28 \text { families, were confirmed to have WD by a } \\
\text { score } \geq 4 \text { points according to the LS } \\
\text { - From the } 34 \text { diagnosed patients, } 23 \text { were new and } \\
11 \text { had been previously reported }\end{array}$ & $\begin{array}{l}\text { Ceruloplasmin lower normal limit (defined } \\
\text { as } 0.1 \mathrm{~g} / \mathrm{L} \text { or } 28 \mathrm{IU} / \mathrm{L} \text { ) }\end{array}$ \\
\hline $\begin{array}{l}\text { Xuan, 2007, } \\
\text { Canada } \\
(22)\end{array}$ & $\begin{array}{l}\text { Prospective study of adult } \\
\text { patients with atypical } \\
\text { presentations of Wilson } \\
\text { Disease }(n=3)\end{array}$ & $\begin{array}{l}\text { - All three of cases showed that the LS provides a } \\
\text { useful framework for diagnosis } \\
\text { - Even without the additional points from positive } \\
\text { mutational analysis, all three patients each scored a } 6 \text {, } \\
\text { placing them in the diagnostic range }\end{array}$ & $\begin{array}{l}\text { - 24-hour urine copper }>0.6 \mathrm{Imol} / 24 \mathrm{~h} \\
\text { - Serum ceruloplasmin }<0.20 \mathrm{~g} / \mathrm{L} \\
\text { - Hepatic copper content }<50 \mathrm{lg} / \mathrm{g}\end{array}$ \\
\hline $\begin{array}{l}\text { Tatsumi, } \\
2011, \\
\text { Japan (51) }\end{array}$ & $\begin{array}{l}\text { Retrospective cohort study } \\
\text { of } 23 \text { pediatric and adult } \\
\text { patients }\end{array}$ & $\begin{array}{l}\text { - } 10 \text { patients had definitive ATP7B variants } \\
\text { - } 9 \text { of these patients had a Leipzig score }>4\end{array}$ & Ceruloplasmin $<10 \mathrm{mg} / \mathrm{dL}$ \\
\hline $\begin{array}{l}\text { Nicastro, } \\
2010, \text { Italy } \\
(21)\end{array}$ & $\begin{array}{l}\text { Case control study of } 40 \\
\text { children with WD ( } 26 \text { boys } \\
\text { and } 14 \text { girls, age range } \\
1.1-20.9 \text { years) and } 58 \\
\text { age-matched and sex- } \\
\text { matched patients with a } \\
\text { liver disease other than } \\
\text { WD }\end{array}$ & $\begin{array}{l}\text { - Ceruloplasmin }<20 \mathrm{mg} / \mathrm{dL} \text { showed a sensitivity of } \\
95 \% \text { and a specificity of } 84.5 \% \\
\text { - Urinary copper }>40 \mathrm{lg} / 24 \text { hours showed a sensitivity } \\
\text { of } 78.9 \% \text { and a specificity of } 87.9 \% \\
\text { - Urinary copper values after penicillamine challenge } \\
\text { did not significantly differ between WD patients and } \\
\text { control subjects (sensitivity of } 12 \% \text { ) } \\
\text { - The LS was proved to have positive and negative } \\
\text { predictive values of } 93 \% \text { and } 91.6 \% \text {, respectively }\end{array}$ & $\begin{array}{l}\text { - Serum ceruloplasmin }<20 \mathrm{mg} / \mathrm{dL} \\
\text { - Urinary copper }>40 \mathrm{lg} / 24 \text { hours }\end{array}$ \\
\hline
\end{tabular}

WD, Wilson Disease; LS, Leipzig Score; PPV, positive predictive value; NPV, negative predictive value. 
Table 2 Summary of clinical and laboratory features of WD and conditions in its differential diagnosis

\begin{tabular}{|c|c|}
\hline Disease & Clinical laboratory features \\
\hline \multirow{3}{*}{ Wilson Disease } & - High urinary copper $(>40 \mu \mathrm{g} /$ day or $>0.6 \mu \mathrm{mol} /$ day) \\
\hline & - Elevated transaminases (often AST > ALT) \\
\hline & - Hemolytic anemia \\
\hline $\begin{array}{l}\text { Non-Alcoholic Fatty Liver } \\
\text { Disease }\end{array}$ & - Alkaline phosphatase may be abnormally elevated two- to threefold, in fewer than half of patients \\
\hline \multirow{4}{*}{$\begin{array}{l}\text { Alcohol-Associated Liver } \\
\text { Disease }\end{array}$} & - Typically have moderately elevated aminotransferases $(<500 \mathrm{IU} / \mathrm{mL})$ with AST:ALT ratio of two or greater \\
\hline & - Elevated serum bilirubin (greater than $5 \mathrm{mg} / \mathrm{dL}$ ) \\
\hline & - Gamma-glutamyl transferase (GGT) is often elevated \\
\hline & - IgA levels are increased in chronic ALD. An increased ratio of $\lg A$ to $\lg G$ is highly suggestive of ALD \\
\hline \multirow[t]{4}{*}{ Autoimmune Hepatitis } & $\begin{array}{l}\text { - Acute: Elevations in ALT and AST levels may exceed } 10 \text { to } 20 \text { times the upper limit of the reference range, } \\
\text { and the ratio of alkaline phosphatase to AST (or ALT) is often }<1: 5 \text {, and in some cases is }<1: 10\end{array}$ \\
\hline & $\begin{array}{l}\text { - Chronic or with cirrhosis: AST and ALT elevations are less profound, while the ratio of alkaline phosphatase } \\
\text { to AST (or ALT) is lower and approaches 1:2 }\end{array}$ \\
\hline & - ANA titers in the range of $1: 80$ to $1: 100$ or greater are regarded as positive in adults \\
\hline & $\begin{array}{l}\text { - Anti-smooth muscle antibodies (ASMA) are more specific than ANA for autoimmune hepatitis, particularly } \\
\text { when present in titers of 1:80 or more }\end{array}$ \\
\hline
\end{tabular}

AST, aspartate transaminase; ALT, alanine transaminase; ALD, alcoholic liver disease.

accumulation in WD can be patchy. Furthermore, presence of mild copper accumulation is common in cholestatic diseases and is therefore not specific for WD.

\section{Non-alcoholic fatty liver disease}

Although there is no unique pattern of elevation for ALT and AST levels in NAFLD, in general, ALT are higher than AST levels and elevations typically are not greater than two times the upper limit of normal, with levels rarely above $300 \mathrm{IU} / 1$ (57-60). The AST/ALT ratio is reported to be less than 1 in $65 \%$ to $90 \%$ of NAFLD patients $(58,59,61)$. Alkaline phosphatase may be twoto threefold above the normal limits in fewer than half of patients whereas bilirubin levels are rarely abnormal, unless cirrhosis is present (62).

Histologically, NASH is characterized by the presence of macrovesicular (large droplet) steatosis, lobular inflammation, and hepatocellular ballooning (Figure 1D). In NASH, the pattern of steatosis may be characterized by either purely large droplets (macrovesicular steatosis) or a mixture of large droplet and focal microvesicular fat (mixed macro- and microvesicular steatosis), the latter of which is associated with more severe disease (63). Although not specific, the pattern and distribution of steatosis can help differentiate WD and NASH. Whereas NASH may show a predominance of zone 3 (peri-central) steatosis, in WD hepatic fat accumulation is typically more evenly distributed across the lobule. Additionally, hepatic steatosis in WD consists primarily of large droplet fat. Interestingly, there is evidence of a possible common genetic mechanism behind the development of steatosis in NAFLD and WD. A single nucleotide polymorphism in the patatin-like phospholipase domain containing 3 gene (PNPLA3), also known as adiponutrin gene, has been shown to be strongly associated with increased hepatic fat content and elevated ALT levels. With the goal to explore the mechanisms underlying the development of hepatic steatosis in $\mathrm{WD}$, a study examined the prevalence of the PNPLA3 G variant in 98 patients with WD. The 


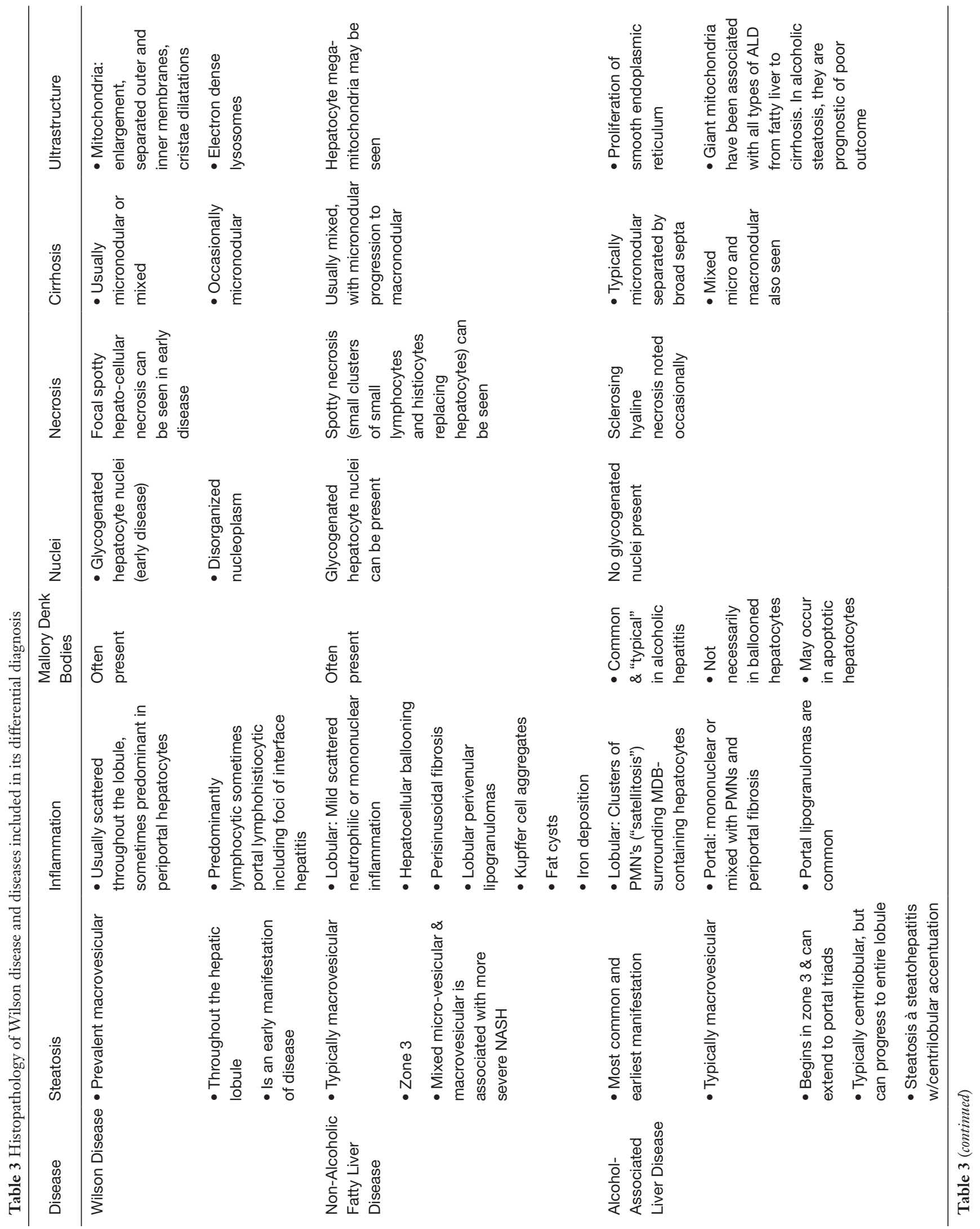




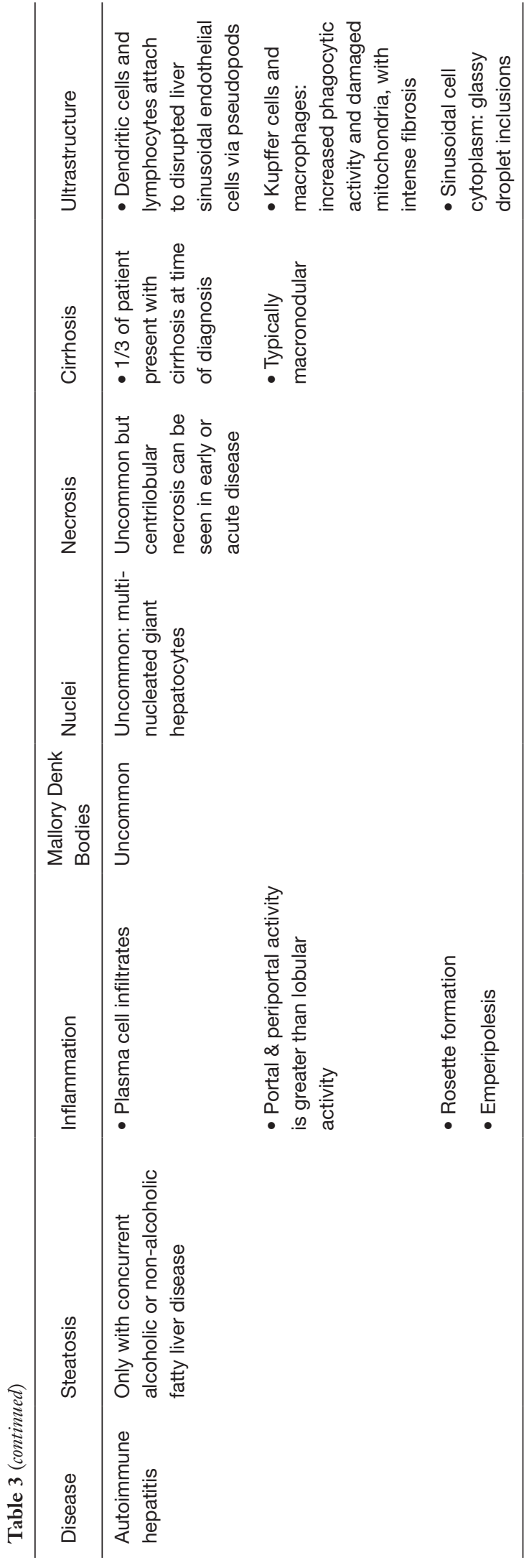

$\mathrm{G}$ allele resulted to be an independent variable associated with moderate to severe steatosis, in contrast with hepatic copper content which was not associated with steatosis or its severity in WD patients (64).

Another similarity between NAFLD and WD histopathology is the high prevalence of GN, which are vacuolated nuclei usually observed in periportal hepatocytes (zone 1) (Figure 1A). GN represent a significant area of overlap between NAFLD and WD that has been noted in the literature as early as 1960 when two pathologists from Mount Sinai Medical Center described "outstanding" glycogen degeneration nuclei in WD (65). At that time, the high frequency with which glycogen accumulation presented within hepatic nuclei was considered similar to the one observed in diabetes. More recently, a cohort study performed at the University Hospital of Lausanne, Switzerland between 2004 and 2016 revealed that GN were present in almost all WD cases, although with variability in the severity of their presentation (17). However, the subtle differences in histologic features do not provide adequate specificity for differentiating WD from NASH, and hepatic copper concentration is the most important and striking difference. One study from Austria compared the hepatic copper concentrations of 124 patients with NAFLD to concentrations in patients with other chronic liver diseases including chronic hepatitis $\mathrm{C}$, hemochromatosis, alcoholic liver disease, AIH, and in control subjects. Hepatic copper concentrations in patients with NAFLD were significantly lower than in control subjects and in patients with other liver diseases. The average concentration in NAFLD patients was $17.9 \pm 8.4$ versus $31.4 \pm 8.2 \mu \mathrm{g} / \mathrm{g}$ in control subjects $(\mathrm{P}<0.001)$. The study also demonstrated an inverse correlation between hepatic copper content and the degree of steatosis. In addition, the same study showed that rats maintained on a copper-deficient diet developed hepatic steatosis and insulin resistance, suggesting that low copper availability may contribute to the pathogenesis of NAFLD (29). Further studies including mitochondrial changes are needed to understand the mechanisms underlying this phenomenon. In summary, steatosis and GN are common in both NAFLD and WD. Subtle histologic features (e.g., distribution and type of steatosis) may help point to either NAFLD or WD, but are insufficiently specific. Thus, interpretation within the clinical context and quantitative copper testing are required for definitive diagnosis. 

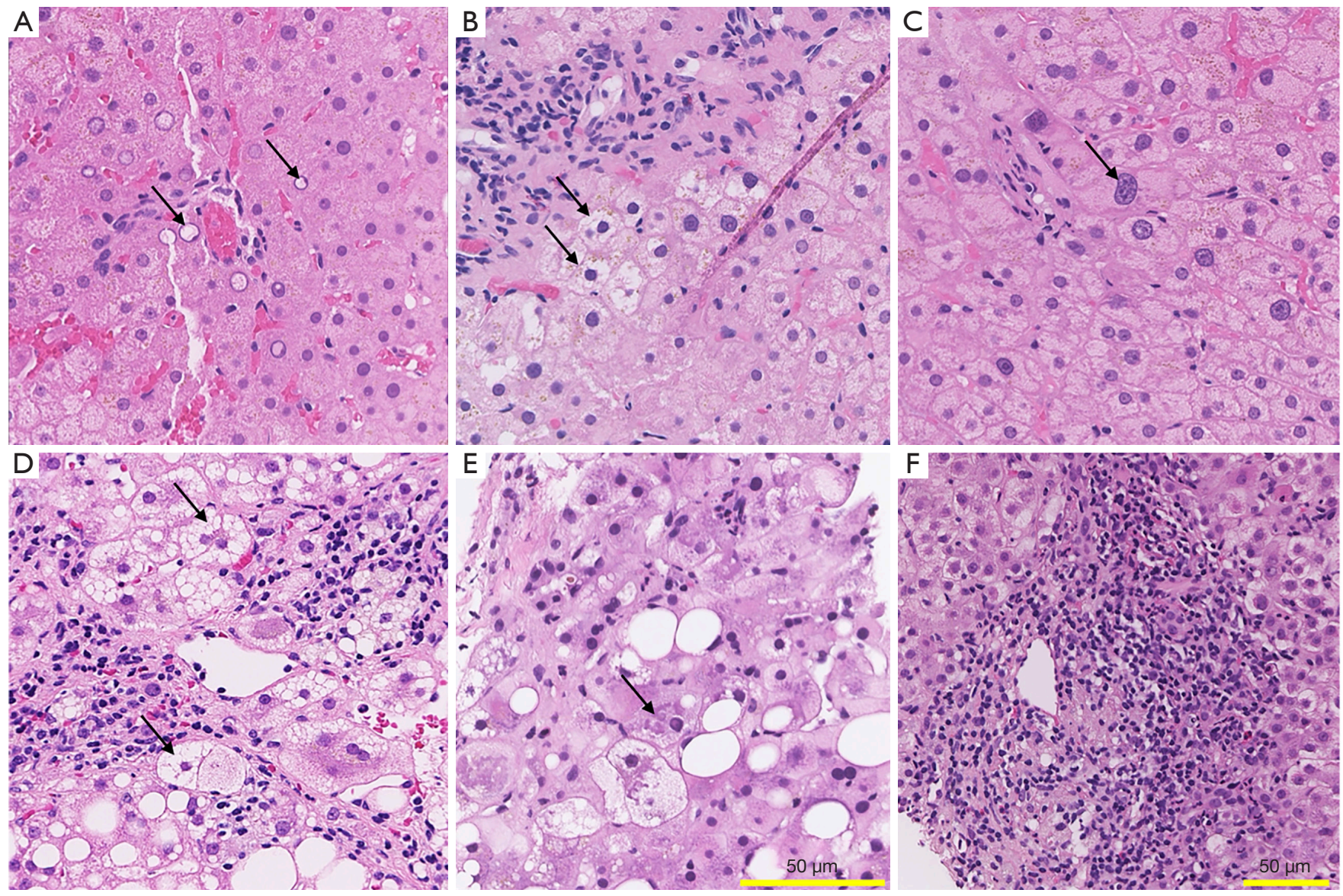

Figure 1 Liver histology of Wilson disease, non-alcoholic steatohepatitis, alcoholic steatohepatitis, and autoimmune hepatitis. (A-C) Wilson disease. (A) Glycogenated nuclei, adjacent to a small portal tract. (B) Ballooning degeneration. (C) Striking anisonucleosis of hepatocytes. (D) Non-alcoholic steatohepatitis. Numerous ballooned hepatocytes are present adjacent to the central venule, along with lobular inflammation.

(E) Alcoholic steatohepatitis. Prominent Mallory-Denk bodies (arrow) are present, as well as discrete foci of lobular injury and cholestasis.

(F) Autoimmune hepatitis. Prominent portal inflammation consisting predominantly of lymphocytes and plasma cells, with rare eosinophils and neutrophils. Inflammation extends into the lobule (i.e., interface activity). A rare acidophil body is noted (top right). Sections are stained with hematoxylin and eosin. Scale bar length is $50 \mu \mathrm{m}$ in all quadrants, one size for quadrants A-E, different size for quadrant F. All images were digitally scanned at 20x magnification.

\section{Alcohol-associated liver disease}

The pattern of liver enzyme elevations in WD has similarities with alcohol-related liver injury and is most commonly seen in conditions associated with mitochondrial damage. In both conditions, AST levels tend to be higher than ALT with AST:ALT ratio greater than 2:1. AST or ALT levels rarely exceed 300 IU/L (66). A higher ratio further increases the likelihood of alcohol-associated liver disease (ALD) $(67,68)$. The first and most common histopathologic change seen in ALD is steatosis (69). This is usually macrovesicular and more prominent in centrilobular regions, but may extend toward the portal triads and involve the entire lobule in severe disease states (70). Lipid vacuoles occupy much of the hepatocyte cytoplasm (i.e., large droplet fat), confining the nucleus and other organelles to the periphery of the cell (71). Macrovesicular steatosis in ALD may be associated with scattered small collections of lymphocytes in the hepatic lobule, potentially indicating emerging steatohepatitis. This type of mild inflammation is similar to lesions identified in previously designated NAFLD type 2, as well as previously described lymphocytic infiltration in WD (58). Hepatocytes may contain megamitochondria, visible on hematoxylin 
and eosin-stained sections as ovoid or rounded eosinophilic cytoplasmic inclusions measuring between 2 to $10 \mu \mathrm{m}$ (72-74), as also seen in WD (75) and NAFLD (76), and are therefore not specific for alcoholic liver injury. These histologic findings are non-specific and do not distinguish alcohol-associated liver disease from WD.

With persistent alcohol use, steatosis can progress to steatohepatitis (SH) $(77,78)$. Generally, $\mathrm{SH}$ affects perivenular regions in its earliest stage (79). Histopathologic findings include steatosis, hepatocellular ballooning, inflammation consisting of neutrophilic and/or lymphocytic infiltrates, intracytoplasmic Mallory-Denk bodies (MDB), and fibrosis with a perivenular, perisinusoidal, and pericellular disposition (Figure 1E). MDB are cytoplasmic hyaline inclusions within hepatocytes with a predominantly filamentous ultrastructure that were first described in 1911 in association with ALD. They are characteristically associated with ALD and NASH, but are also found in a variety of other liver diseases including chronic cholestasis (especially due to primary biliary cholangitis), certain types of drug induced liver injury (e.g., amiodarone toxicity), alpha 1 antitrypsin deficiency, idiopathic copper toxicosis, and hepatic focal nodular hyperplasia $(80,81)$. MDB are also seen in up to $50 \%$ of WD patients (82). Inflammation in ASH is typically neutrophil-rich, in contrast to WD which has a lymphocytic predominant pattern. Mild portal lymphocytic infiltrates may be present in some cases of ASH but are less common. Perivenular and perisinusoidal fibrosis are characteristic features of both alcohol-related and non-alcohol related steatohepatitis. Hepatic necrosis and inflammation are activators of perisinusoidal stellate cells, which initiate fibrogenesis to create a "chicken-wire" or "spider-like" pattern of fibrosis in centrilobular regions (71). Diffuse hepatocellular ballooning and cholestasis in the setting of cirrhosis is often seen in acute liver failure due to ALD. In general, abundant neutrophils and MDB are features that would favor alcohol-associated liver disease, whereas substantial macrovesicular steatosis and lymphocytic infiltrates would be more suggestive of WD or NAFLD.

\section{Autoimmune bepatitis}

AIH can present with mild, moderate or marked $(>1,000$ IU/L) increase in aminotransferase levels (83). Patients often develop a chronic hepatitis picture with persistent elevation of transaminase levels. Less commonly, AIH can manifest with concomitant cholestasis with high levels of conjugated bilirubin and alkaline phosphatase (84).
$\mathrm{AIH}$ is included in the differential diagnosis of WD both in the early and later stages. In addition, WD can also present with similarly elevated immunoglobulins and autoantibodies $(85,86)$. AIH histology is characterized by the presence of interface hepatitis (with necrosis of hepatocytes at the interface of hepatic parenchyma and the periportal zone), portal lymphocyte and plasma cell infiltration, hepatocyte rosette formation, and emperipolesis (Figure $1 \mathrm{~F}$ ). Pre-treatment liver biopsies in patients with AIH reveal histological features of both acute and chronic hepatitis with accompanying various degrees of fibrosis. The most prominent features are centrilobular necrosis/inflammation, interface hepatitis, plasma cell infiltration, emperipolesis, pigmented macrophages, cobblestone appearance of hepatocytes and perivenular necroinflammatory activity $(87,88)$. WD liver pathology can have features that are indistinguishable from acute and chronic AIH. In both $\mathrm{WD}$ and $\mathrm{AIH}$, inflammatory infiltrates can extend from the portal tract into the lobule, with accompanying active interface hepatitis. Inflammation may be also seen scattered throughout the lobule, leading to damage and necrosis of small groups of hepatocytes. Both portal and lobular hepatitis can coexist. Interestingly, case reports indicate the histological features of WD at diagnosis can resemble those of AIH (86) or WD can co-exist with AIH (89). The differential diagnosis between WD and AIH remains among the most challenging especially in the acute setting and has implications for treatment choices and liver transplantation evaluation. Hepatic copper quantification is an important parameter when distinguishing the two entities, as normal copper hepatic levels would at least argue against WD. Moreover, it is reasonable to consider diagnostic assessment of WD in cases of AIH that are partially responsive or nonresponsive to immunosuppression.

\section{Liver histology progression}

The natural history of liver damage in WD is not well known as all long-term follow up studies describe the evolution of histological parameters of liver disease while on anti-copper treatment, and no reports exist on the true natural history of untreated WD. It is evident that the natural history of WD liver pathology can be modified by treatment, although the response to treatment is variable and not predictable $(90,91)$. A study of $12 \mathrm{WD}$ patients who underwent serial liver biopsies described the progression of liver fibrosis, inflammation, and steatosis over a mean follow up of 5 years (range, 1-12 years). 
Patients were treated with penicillamine or zinc. The estimated rate of hepatic fibrosis progression was of 0 unit of fibrosis stage ( $0-4$ stage scale) in the time between the first and the second follow up liver biopsy and 0.25 unit of fibrosis stage in the time between the second and third liver biopsy. Overall, half of the patients did not manifest histological progression while the remaining half had progression of fibrosis. However, this difference could be confounded by selection bias. Biopsies were performed only when clinically indicated and when patients failed to appropriately respond to medical therapy, with likely inclusion of patients in worse clinical conditions. Multiple other studies have shown variable improvement of steatosis, inflammation grade (92), and the fibrosis stage $(90,93)$ of WD livers during long-term follow-up after treatment with chelating agents and/or zinc salts. A study from Italy described 40 patients who underwent a liver biopsy at baseline and at least one second liver biopsy over more than 20 years of follow up (94). Eighty-three percent of patients presented stable or improved liver fibrosis, and the remaining presented worsened histology with no correlation between histological findings and type of treatment or liver enzymes. A study on a group of 22 pediatric subjects, all treated with zinc sulfate, showed improvement in parameters of inflammation, steatosis, and fibrosis over 10 years of follow-up (92). Askari et al. studied the combination treatment with zinc and trientine in 3 WD patients with cirrhosis. In one case, cirrhosis improved to stage 1 fibrosis, whereas the other 2 cases were stable or slightly improved to stage 3 (90). Given the variability of liver histology description and scoring, it is difficult to draw strong conclusions on the effects of the anti-copper treatments of histological parameters and long-term studies utilizing uniform criteria are needed.

\section{Features of hepatic involvement in WD}

\section{Hepatic malignancies}

Hepatic malignancies, and in particular hepatocellular carcinoma (HCC) and cholangiocarcinoma (CC), are frequent complications of liver diseases, both with and without cirrhosis. However, there is mixed evidence on the risk of HCC in WD, regardless of the presence of advanced stage of fibrosis. The two types of malignant hepatobiliary tumors that have been documented in WD are HCC and CC. The prevalence of hepatobiliary malignancies in patients with $W D$ is $1.2 \%$ and the incidence is $28 / 100,000$. In the largest published series involving $1,186 \mathrm{WD}$ patients, 14 were found to have hepatobiliary malignancies. Eight patients had HCC and six had intrahepatic CC (95). A large retrospective study of 211 WD patients from Hong Kong showed that three of the ones with liver involvement also developed HCC (96). Although HCC is uncommon in cirrhosis related to WD, $7 \%$ of cases in a Saudi Arabian cohort also presented a diagnosis of HCC (97). A study gathering data from three Dutch hospitals and 130 patients with WD, 57\% of which had cirrhosis, followed for a median follow up of 15 years, indicated that there is no increased risk of HCC in cirrhosis with an estimated annual HCC risk for all patients of $0.09 \%$ (98). However, these studies are limited by their retrospective design. Patients who were lost to follow up may have developed hepatobiliary malignancy that was not captured, and those who died of natural causes may have had undiagnosed malignancies. Case reports also aid in the characterization of HCC features in WD (99) but ultimately no firm conclusions can be drawn on the risk of malignancy in WD. It is believed that cirrhosis in WD leads to neoplastic transformation through a mechanism similar to that of viral or alcoholic cirrhosis (100-102). CC has been reported less frequently than HCC in WD patients. It is exceedingly rare and to date only a few cases have been described $(103,104)$. CC in WD patients is predominantly intrahepatic, peripheral, and mass-forming tumors, but more diffuse and infiltrative forms have been reported. CC can also be diagnosed during continuous, long term anticopper treatment (104). In approximately $50 \%$ of patients with WD, liver nodules may be identified on imaging, the majority of which are benign. Regenerative nodules, siderotic nodules, focal steatosis or nodular fatty infiltration, pseudotumor honeycomb pattern (multiple nodules), and dysplastic nodules have been previously documented (105).

\section{Acute liver failure}

Acute liver failure is a frequently described presentation of WD (also named "Wilsonian" liver failure) and it has features that differentiate it from other etiologies. In particular, it is characterized by higher prevalence in female patients, Coombs-negative hemolytic anemia, coagulopathy, AST increase that might be relatively modest, and normal or low alkaline phosphatase levels (106). One study in WD cases of acute liver failure found that a ratio of ALT to AST of more than 2.2 had a sensitivity of $94 \%$ and a specificity of $86 \%$, whereas alkaline phosphatase 
to total bilirubin ratio of less than 4 was found to have a sensitivity of $94 \%$ and a specificity of $96 \%$ (107) for the diagnosis of WD. A characteristic feature of Wilsonian acute liver failure is the high mortality without liver transplant with rare described cases of survival without liver transplant $(16,108,109)$. Plasmapheresis/plasma exchange has been implemented as a bridge to the transplant with promising results (110-112).

\section{Ultrastructural bepatic changes}

Some ultrastructural hepatic changes are characteristic of WD, although they are not pathognomonic and can be identified in other etiologies of liver disease, particularly those associated with hepatic copper accumulation. Electron microscope examination can identify mitochondrial and lysosomal changes that have been described in the early phases of liver damage and hepatic copper accumulation both in humans and in animal models of WD (75). Well described morphological alterations of the mitochondria include organelle enlargement, separated outer and inner membranes, and cristae dilatations $(10,75,113-115)$. In addition, electron dense lysosomes, believed to be the sites of copper accumulation, have been reported (116). Nuclei are also frequently involved, with disorganization of the nucleoplasm and glycogen inclusions (117).

\section{Summary}

WD represents a diagnostic challenge and ultimately cases are often overlooked with consequent diagnostic delays. This rare disease presents many clinical and liver histological features that are also observed in common liver diseases. In addition, WD can co-exist with other liver diseases, including NAFLD, alcohol-associated liver disease and AIH. The above is an overview of WD clinical and histopathologic presentation with particular focus on its differential diagnosis.

\section{Acknowledgments}

Funding: The research was supported by the National Institutes of Health through grant number R01DK104770 (to VM).

\section{Footnote}

Reporting Checklist: The authors have completed the
Narrative Review reporting checklist. Available at https:// dx.doi.org/10.21037/atm-21-2264

Peer Review File: Available at https://dx.doi.org/10.21037/ atm-21-2264

Conflicts of Interest: All authors have completed the ICMJE uniform disclosure form (available at https:// dx.doi.org/10.21037/atm-21-2264). Valentina Medici reports that she serves in the Advisory Board for Alexion Pharmaceuticals. The other authors have no conflicts of interest to declare.

Ethical Statement: The authors are accountable for all aspects of the work in ensuring that questions related to the accuracy or integrity of any part of the work are appropriately investigated and resolved.

Open Access Statement: This is an Open Access article distributed in accordance with the Creative Commons Attribution-NonCommercial-NoDerivs 4.0 International License (CC BY-NC-ND 4.0), which permits the noncommercial replication and distribution of the article with the strict proviso that no changes or edits are made and the original work is properly cited (including links to both the formal publication through the relevant DOI and the license). See: https://creativecommons.org/licenses/by-nc-nd/4.0/.

\section{References}

1. Tanzi RE, Petrukhin K, Chernov I, et al. The Wilson disease gene is a copper transporting ATPase with homology to the Menkes disease gene. Nat Genet 1993;5:344-50.

2. Bull PC, Thomas GR, Rommens JM, et al. The Wilson disease gene is a putative copper transporting P-type ATPase similar to the Menkes gene. Nat Genet 1993;5:327-37.

3. Shah AB, Chernov I, Zhang HT, et al. Identification and analysis of mutations in the Wilson disease gene (ATP7B): population frequencies, genotype-phenotype correlation, and functional analyses. Am J Hum Genet 1997;61:317-28.

4. Medici V, LaSalle JM. Genetics and epigenetic factors of Wilson disease. Ann Transl Med 2019;7:S58.

5. Roelofsen H, Wolters H, Van Luyn MJ, et al. Copperinduced apical trafficking of ATP7B in polarized hepatoma cells provides a mechanism for biliary copper excretion. Gastroenterology 2000;119:782-93. 
6. Goldfischer S, Sternlieb I. Changes in the distribution of hepatic copper in relation to the progression of Wilson's disease (hepatolenticular degeneration). Am J Pathol 1968;53:883-901.

7. Huster D, Finegold MJ, Morgan CT, et al. Consequences of copper accumulation in the livers of the Atp7b-/(Wilson disease gene) knockout mice. Am J Pathol 2006;168:423-34.

8. Huster D, Purnat TD, Burkhead JL, et al. High copper selectively alters lipid metabolism and cell cycle machinery in the mouse model of Wilson disease. J Biol Chem 2007;282:8343-55.

9. Zischka H, Lichtmannegger J. Pathological mitochondrial copper overload in livers of Wilson's disease patients and related animal models. Ann N Y Acad Sci 2014;1315:6-15.

10. Zischka H, Lichtmannegger J, Schmitt S, et al. Liver mitochondrial membrane crosslinking and destruction in a rat model of Wilson disease. J Clin Invest 2011;121:1508-18.

11. Meacham KA, Cortés MP, Wiggins EM, et al. Altered zinc balance in the Atp7b-/- mouse reveals a mechanism of copper toxicity in Wilson disease. Metallomics 2018;10:1595-606.

12. Ralle M, Huster D, Vogt S, et al. Wilson disease at a single cell level: intracellular copper trafficking activates compartment-specific responses in hepatocytes. J Biol Chem 2010;285:30875-83.

13. Ferenci P, Członkowska A, Merle U, et al. Late-onset Wilson's disease. Gastroenterology 2007;132:1294-8.

14. Merle U, Schaefer M, Ferenci P, et al. Clinical presentation, diagnosis and long-term outcome of Wilson's disease: a cohort study. Gut 2007;56:115-20.

15. Medici V, Mirante VG, Fassati LR, et al. Liver transplantation for Wilson's disease: The burden of neurological and psychiatric disorders. Liver Transpl 2005;11:1056-63.

16. Eisenbach C, Sieg O, Stremmel W, et al. Diagnostic criteria for acute liver failure due to Wilson disease. World J Gastroenterol 2007;13:1711-4.

17. Vieira Barbosa J, Fraga M, Saldarriaga J, et al. Hepatic manifestations of Wilson's disease: 12-year experience in a Swiss tertiary referral centre. Swiss Med Wkly 2018;148:w14699.

18. Santos RG, Alissa F, Reyes J, et al. Fulminant hepatic failure: Wilson's disease or autoimmune hepatitis? Implications for transplantation. Pediatr Transplant 2005;9:112-6.

19. Patel R. Wilson disease: a diagnostic challenge in a patient with alcoholic liver disease. BMJ Case Rep 2019; 12:232449.

20. Mahmood S, Inada N, Izumi A, et al. Wilson's disease masquerading as nonalcoholic steatohepatitis. N Am J Med Sci 2009;1:74-6.

21. Nicastro E, Ranucci G, Vajro P, et al. Re-evaluation of the diagnostic criteria for Wilson disease in children with mild liver disease. Hepatology 2010;52:1948-56.

22. Xuan A, Bookman I, Cox DW, et al. Three atypical cases of Wilson disease: assessment of the Leipzig scoring system in making a diagnosis. J Hepatol 2007;47:428-33.

23. Ryan A, Nevitt SJ, Tuohy O, et al. Biomarkers for diagnosis of Wilson's disease. Cochrane Database Syst Rev 2019;2019.

24. Durand F, Bernuau J, Giostra E, et al. Wilson's disease with severe hepatic insufficiency: beneficial effects of early administration of D-penicillamine. Gut 2001;48:849-52.

25. Devarbhavi H, Singh R, Adarsh CK, et al. Factors that predict mortality in children with Wilson disease associated acute liver failure and comparison of Wilson disease specific prognostic indices. J Gastroenterol Hepatol 2014;29:380-6.

26. Hermann $W$. Classification and differential diagnosis of Wilson's disease. Ann Transl Med 2019;7:S63.

27. European Association for Study of Liver. EASL Clinical Practice Guidelines: Wilson's disease. J Hepatol 2012;56:671-85.

28. Gong A, Leitold S, Uhanova J, et al. Non-Wilson's Disease-Associated Hypoceruloplasminemia. J Clin Exp Hepatol 2020;10:284-9.

29. Aigner E, Strasser M, Haufe H, et al. A role for low hepatic copper concentrations in nonalcoholic Fatty liver disease. Am J Gastroenterol 2010;105:1978-85.

30. Walshe JM. The pattern of urinary copper excretion and its response to treatment in patients with Wilson's disease. QJM 2011;104:775-8.

31. Steindl P, Ferenci P, Dienes HP, et al. Wilson's disease in patients presenting with liver disease: a diagnostic challenge. Gastroenterology 1997;113:212-8.

32. Giacchino R, Marazzi MG, Barabino A, et al. Syndromic variability of Wilson's disease in children. Clinical study of 44 cases. Ital J Gastroenterol Hepatol 1997;29:155-61.

33. Sánchez-Albisua I, Garde T, Hierro L, et al. A high index of suspicion: the key to an early diagnosis of Wilson's disease in childhood. J Pediatr Gastroenterol Nutr 1999;28:186-90.

34. Frommer DJ. Urinary copper excretion and hepatic copper concentrations in liver disease. Digestion 1981;21:169-78. 
35. Martins da Costa C, Baldwin D, Portmann B, et al. Value of urinary copper excretion after penicillamine challenge in the diagnosis of Wilson's disease. Hepatology 1992;15:609-15.

36. Przybyłkowski A, Szeligowska J, Januszewicz M, et al. Evaluation of liver fibrosis in patients with Wilson's disease. Eur J Gastroenterol Hepatol 2021;33:535-40.

37. Paternostro R, Pfeiffenberger J, Ferenci P, et al. Noninvasive diagnosis of cirrhosis and long-term disease monitoring by transient elastography in patients with Wilson disease. Liver Int 2020;40:894-904.

38. Yang X, Tang XP, Zhang YH, et al. Prospective evaluation of the diagnostic accuracy of hepatic copper content, as determined using the entire core of a liver biopsy sample. Hepatology 2015;62:1731-41.

39. Ferenci P, Steindl-Munda P, Vogel W, et al. Diagnostic value of quantitative hepatic copper determination in patients with Wilson's Disease. Clin Gastroenterol Hepatol 2005;3:811-8.

40. Członkowska A, Rodo M, Wierzchowska-Ciok A, et al. Accuracy of the radioactive copper incorporation test in the diagnosis of Wilson disease. Liver Int 2018;38:1860-6.

41. Peng F. Positron emission tomography for measurement of copper fluxes in live organisms. Ann N Y Acad Sci 2014;1314:24-31.

42. Collins CJ, Yi F, Dayuha R, et al. Direct Measurement of ATP7B Peptides Is Highly Effective in the Diagnosis of Wilson Disease. Gastroenterology 2021;160:2367-2382.e1.

43. Medici V. Expanding the Diagnostic Toolkit of Wilson Disease with ATP7B Peptides. Gastroenterology 2021;160:2249-51.

44. Broniek-Kowalik K, Dzieżyc K, Litwin T, et al. Anterior segment optical coherence tomography (AS-OCT) as a new method of detecting copper deposits forming the Kayser-Fleischer ring in patients with Wilson disease. Acta Ophthalmol 2019;97:e757-60.

45. Sridhar MS. Advantages of Anterior Segment Optical Coherence Tomography Evaluation of the KayserFleischer Ring in Wilson Disease. Cornea 2017;36:343-6.

46. Ferenci P, Caca K, Loudianos G, et al. Diagnosis and phenotypic classification of Wilson disease. Liver Int 2003;23:139-42.

47. Koppikar S, Dhawan A. Evaluation of the scoring system for the diagnosis of Wilson's disease in children. Liver Int 2005;25:680-1.

48. Moores A, Fox S, Lang A, et al. Wilson disease: Canadian perspectives on presentation and outcomes from an adult ambulatory setting. Can J Gastroenterol 2012;26:333-9.
49. Penon-Portmann M, Lotz-Esquivel S, Chavez Carrera A, et al. Wilson disease in Costa Rica: Pediatric phenotype and genotype characterization. JIMD Rep 2020;52:55-62.

50. Abdel Ghaffar TY, Elsayed SM, Elnaghy S, et al. Phenotypic and genetic characterization of a cohort of pediatric Wilson disease patients. BMC Pediatr 2011;11:56.

51. Tatsumi Y, Shinohara T, Imoto M, et al. Potential of the international scoring system for the diagnosis of Wilson disease to differentiate Japanese patients who need anticopper treatment. Hepatol Res 2011;41:887-96.

52. Gow PJ, Smallwood RA, Angus PW, et al. Diagnosis of Wilson's disease: an experience over three decades. Gut 2000;46:415-9.

53. Ludwig J, Moyer TP, Rakela J. The liver biopsy diagnosis of Wilson's disease. Methods in pathology. Am J Clin Pathol 1994;102:443-6.

54. Stromeyer FW, Ishak KG. Histology of the liver in Wilson's disease: a study of 34 cases. Am J Clin Pathol 1980;73:12-24.

55. Emanuele P, Goodman ZD. A simple and rapid stain for copper in liver tissue. Ann Diagn Pathol 1998;2:125-6.

56. Szerdahelyi P, Kása P. Histochemistry of zinc and copper. Int Rev Cytol 1984;89:1-33.

57. Kwo PY, Cohen SM, Lim JK. ACG Clinical Guideline: Evaluation of Abnormal Liver Chemistries. Am J Gastroenterol 2017;112:18-35.

58. Matteoni CA, Younossi ZM, Gramlich T, et al. Nonalcoholic fatty liver disease: a spectrum of clinical and pathological severity. Gastroenterology 1999;116:1413-9.

59. Angulo P, Keach JC, Batts KP, et al. Independent predictors of liver fibrosis in patients with nonalcoholic steatohepatitis. Hepatology 1999;30:1356-62.

60. Sorbi D, Boynton J, Lindor KD. The ratio of aspartate aminotransferase to alanine aminotransferase: potential value in differentiating nonalcoholic steatohepatitis from alcoholic liver disease. Am J Gastroenterol 1999;94:1018-22.

61. Bacon BR, Farahvash MJ, Janney CG, et al. Nonalcoholic steatohepatitis: an expanded clinical entity. Gastroenterology 1994;107:1103-9.

62. McCullough AJ. The clinical features, diagnosis and natural history of nonalcoholic fatty liver disease. Clin Liver Dis 2004;8:521-33, viii.

63. Takahashi Y, Fukusato T. Histopathology of nonalcoholic fatty liver disease/nonalcoholic steatohepatitis. World J Gastroenterol 2014;20:15539-48.

64. Stättermayer AF, Traussnigg S, Dienes HP, et al. Hepatic steatosis in Wilson disease--Role of copper and PNPLA3 
mutations. J Hepatol 2015;63:156-63.

65. ANDERSON PJ, POPPER H. Changes in hepatic structure in Wilson's disease. Am J Pathol 1960;36:483-97.

66. Cohen JA, Kaplan MM. The SGOT/SGPT ratio-an indicator of alcoholic liver disease. Dig Dis Sci 1979;24:835-8.

67. Sharpe PC. Biochemical detection and monitoring of alcohol abuse and abstinence. Ann Clin Biochem 2001;38:652-64.

68. Hietala J, Puukka K, Koivisto H, et al. Serum gammaglutamyl transferase in alcoholics, moderate drinkers and abstainers: effect on gt reference intervals at population level. Alcohol Alcohol 2005;40:511-4.

69. Rubin E, Lieber CS. Effect of alcohol on liver. N Engl J Med 1968;279:46-7.

70. Theise ND. Histopathology of alcoholic liver disease. Clin Liver Dis (Hoboken) 2013;2:64-7.

71. Lefkowitch JH. Morphology of alcoholic liver disease. Clin Liver Dis 2005;9:37-53.

72. Uchida T, Kronborg I, Peters RL. Giant mitochondria in the alcoholic liver diseases--their identification, frequency and pathologic significance. Liver 1984;4:29-38.

73. Fromenty B, Grimbert S, Mansouri A, et al. Hepatic mitochondrial DNA deletion in alcoholics: association with microvesicular steatosis. Gastroenterology 1995;108:193-200.

74. Chedid A, Mendenhall CL, Tosch T, et al. Significance of megamitochondria in alcoholic liver disease.

Gastroenterology 1986;90:1858-64.

75. Sternlieb I. Mitochondrial and fatty changes in hepatocytes of patients with Wilson's disease. Gastroenterology 1968;55:354-67.

76. Le TH, Caldwell SH, Redick JA, et al. The zonal distribution of megamitochondria with crystalline inclusions in nonalcoholic steatohepatitis. Hepatology 2004;39:1423-9.

77. Lischner MW, Alexander JF, Galambos JT. Natural history of alcoholic hepatitis. I. The acute disease. Am J Dig Dis 1971;16:481-94.

78. Barrio E, Tomé S, Rodríguez I, et al. Liver disease in heavy drinkers with and without alcohol withdrawal syndrome. Alcohol Clin Exp Res 2004;28:131-6.

79. Sohail U, Satapathy SK. Diagnosis and management of alcoholic hepatitis. Clin Liver Dis 2012;16:717-36.

80. Madakshira MG, Das A, Umairv M, et al. Liver histology and histochemistry in Wilson disease. Autops Case Rep 2018;8:e2018026.

81. Denk H, Stumptner C, Zatloukal K. Mallory bodies revisited. J Hepatol 2000;32:689-702.

82. Zatloukal K, French SW, Stumptner C, et al. From Mallory to Mallory-Denk bodies: what, how and why? Exp Cell Res 2007;313:2033-49.

83. Al-Chalabi T, Underhill JA, Portmann BC, et al. Effects of serum aspartate aminotransferase levels in patients with autoimmune hepatitis influence disease course and outcome. Clin Gastroenterol Hepatol 2008;6:1389-95; quiz 1287.

84. Krawitt EL. Autoimmune hepatitis. N Engl J Med 2006;354:54-66.

85. Scott J, Gollan JL, Samourian S, et al. Wilson's disease, presenting as chronic active hepatitis. Gastroenterology 1978;74:645-51.

86. Milkiewicz P, Saksena S, Hubscher SG, et al. Wilson's disease with superimposed autoimmune features: report of two cases and review. J Gastroenterol Hepatol 2000;15:570-4.

87. de Boer YS, van Nieuwkerk CM, Witte BI, et al. Assessment of the histopathological key features in autoimmune hepatitis. Histopathology 2015;66:351-62.

88. Balitzer D, Shafizadeh N, Peters MG, et al. Autoimmune hepatitis: review of histologic features included in the simplified criteria proposed by the international autoimmune hepatitis group and proposal for new histologic criteria. Mod Pathol 2017;30:773-83.

89. Yener S, Akarsu M, Karacanci C, et al. Wilson's disease with coexisting autoimmune hepatitis. J Gastroenterol Hepatol 2004;19:114-6.

90. Askari FK, Greenson J, Dick RD, et al. Treatment of Wilson's disease with zinc. XVIII. Initial treatment of the hepatic decompensation presentation with trientine and zinc. J Lab Clin Med 2003;142:385-90.

91. Cope-Yokoyama S, Finegold MJ, Sturniolo GC, et al. Wilson disease: histopathological correlations with treatment on follow-up liver biopsies. World J Gastroenterol 2010;16:1487-94.

92. Marcellini M, Di Ciommo V, Callea F, et al. Treatment of Wilson's disease with zinc from the time of diagnosis in pediatric patients: a single-hospital, 10-year follow-up study. J Lab Clin Med 2005;145:139-43.

93. Linn FH, Houwen RH, van Hattum J, et al. Longterm exclusive zinc monotherapy in symptomatic Wilson disease: experience in 17 patients. Hepatology 2009;50:1442-52.

94. Sini M, Sorbello O, Sanna F, et al. Histologic evolution and long-term outcome of Wilson's disease: results of a single-center experience. Eur J Gastroenterol Hepatol 
2013;25:111-7.

95. Pfeiffenberger J, Mogler C, Gotthardt DN, et al. Hepatobiliary malignancies in Wilson disease. Liver Int 2015;35:1615-22.

96. Cheung KS, Seto WK, Fung J, et al. Epidemiology and natural history of Wilson's disease in the Chinese: A territory-based study in Hong Kong between 2000 and 2016. World J Gastroenterol 2017;23:7716-26.

97. Al Fadda M, Al Quaiz M, Al Ashgar H, et al. Wilson disease in 71 patients followed for over two decades in a tertiary center in Saudi Arabia: a retrospective review. Ann Saudi Med 2012;32:623-9.

98. van Meer S, de Man RA, van den Berg AP, et al. No increased risk of hepatocellular carcinoma in cirrhosis due to Wilson disease during long-term follow-up. J Gastroenterol Hepatol 2015;30:535-9.

99. Harada M. Wilson disease and hepatocellular carcinoma. Intern Med 2004;43:1012-3.

100.Xu R, Bu-Ghanim M, Fiel MI, et al. Hepatocellular carcinoma associated with an atypical presentation of Wilson's disease. Semin Liver Dis 2007;27:122-7.

101.Agret F, Vallet-Pichard A, Landau A, et al. Late presentation of Wilson's disease as cirrhosis complicating hepatocellular carcinoma. Gastroenterol Clin Biol 2003;27:130-1.

102. Suriawinata A, Xu R. An update on the molecular genetics of hepatocellular carcinoma. Semin Liver Dis 2004;24:77-88.

103.Mukai Y, Wada H, Eguchi H, et al. Intrahepatic cholangiocarcinoma in a patient with Wilson's disease: a case report. Surg Case Rep 2016;2:29.

104. Németh D, Folhoffer A, Smuk G, et al. Cholangiocarcinoma in Wilson's Disease - a Case Report. J Gastrointestin Liver Dis 2017;26:305-8.

105.Dohan A, Vargas O, Dautry R, et al. MR imaging features of focal liver lesions in Wilson disease. Abdom Radiol (NY) 2016;41:1811-24.

106.Ahmad A, Torrazza-Perez E, Schilsky ML. Liver transplantation for Wilson disease. Handb Clin Neurol 2017;142:193-204.

Cite this article as: Schroeder SM, Matsukuma KE, Medici V. Wilson disease and the differential diagnosis of its hepatic manifestations: a narrative review of clinical, laboratory, and liver histological features. Ann Transl Med 2021;9(17):1394. doi: 10.21037/atm-21-2264
107. Korman JD, Volenberg I, Balko J, et al. Screening for Wilson disease in acute liver failure: a comparison of currently available diagnostic tests. Hepatology 2008;48:1167-74.

108. Camarata MA, Gottfried M, Rule JA, et al. Outcomes of Acute Liver Injury in Adults Due to Wilson's Disease: Is Survival Without Transplant Possible? Liver Transpl 2020;26:330-6.

109. Kido J, Matsumoto S, Sakamoto R, et al. Recovery of severe acute liver failure without transplantation in patients with Wilson disease. Pediatr Transplant 2018;22:e13292.

110. Nagata Y, Uto H, Hasuike S, et al. Bridging use of plasma exchange and continuous hemodiafiltration before living donor liver transplantation in fulminant Wilson's disease. Intern Med 2003;42:967-70.

111. Sukezaki A, Chu PS, Shinoda M, et al. Late-onset acute liver failure due to Wilson's disease managed by plasmapheresis and hemodiafiltration successfully serving as a bridge for deceased donor liver transplantation: a case report and literature review. Clin J Gastroenterol 2020;13:1239-46.

112.Asfaha S, Almansori M, Qarni U, et al. Plasmapheresis for hemolytic crisis and impending acute liver failure in Wilson disease. J Clin Apher 2007;22:295-8.

113.Lichtmannegger J, Leitzinger C, Wimmer R, et al. Methanobactin reverses acute liver failure in a rat model of Wilson disease. J Clin Invest 2016;126:2721-35.

114. Sternlieb I. Fraternal concordance of types of abnormal hepatocellular mitochondria in Wilson's disease. Hepatology 1992;16:728-32.

115.Sternlieb I, Feldmann G. Effects of anticopper therapy on hepatocellular mitochondria in patients with Wilson's disease: an ultrastructural and stereological study. Gastroenterology 1976;71:457-61.

116. Pronicki M. Wilson disease - liver pathology. Handb Clin Neurol 2017;142:71-5.

117.Fanni D, Fanos V, Gerosa C, et al. Effects of iron and copper overload on the human liver: an ultrastructural study. Curr Med Chem 2014;21:3768-74. 